\title{
A comparison of a new transtelephonic portable spirometer with a laboratory spirometer
}

\author{
G. Izbicki ${ }^{\#}$, S. Abboud*, P. Jordan ${ }^{\#}$, A.P. Perruchoud ${ }^{\#}$, C.T. Bolliger ${ }^{\#}$
}

A comparison of a new transtelephonic portable spirometer with a laboratory spirometer. G. Izbicki, S. Abboud, P. Jordan, A.P. Perruchoud, C.T. Bolliger. (C)ERS Journals Ltd 1999. ABSTRACT: The Spirophone is a new, portable transtelephonic spirometer which records the slow and the forced expiratory vital capacity tests. Data can be transmitted via the telephone to a remote receiving centre, where a volume-time curve and the flow-volume curve are displayed on screen in real time. The aim of this study was to compare the newly developed transtelephonic spirometer, with a laboratory spirometer according to the American Thoracic Society (ATS) testing guidelines.

Spirometry indices (slow vital capacity (SVC), forced vital capacity (FVC), forced expiratory volume in one second (FEV1), peak expiratory flow (PEF), forced expiratory flow at 25, 50 and $75 \%$ of FVC (FEF25, FEF50, and FEF75, respectively)) were measured from the SVC and the FVC tests in 45 subjects (30 patients, 15 healthy volunteers) according to the ATS standards. The data obtained with the laboratory system were compared to those from the Spirophone.

The Spirophone measurements of SVC, FVC, FEV1, PEF, FEF25, FEF50 and FEF75 correlated closely $(r=0.91-0.98)$ to those from the laboratory system, whereas FEF25, FEF50, and FEF75 were significantly higher with the Spirophone.

It is concluded that the Spirophone is comparable to the standard spirometry for home monitoring of slow vital capacity, forced vital capacity, forced expiratory volume in one second and peak expiratory flow. The validity of the manoeuvre can be assessed on screen in real time.

Eur Respir J 1999; 14: 209-213.

Patient home monitoring of peak expiratory flow (PEF) with a peak flow meter (PFM) is increasingly advocated as an aid to the better management of asthma, chronic obstructive pulmonary disease, and after lung transplantation $[1,2,3]$. However, the main limitations of the PFM are the wide individual variations and the inability to validate a correct patient performance of the forced expiratory manoeuvre (FEM) [2]. The introduction of a new portable spirometer (fig. 1) (SPIROPHONE AG-SP; Card Guard,

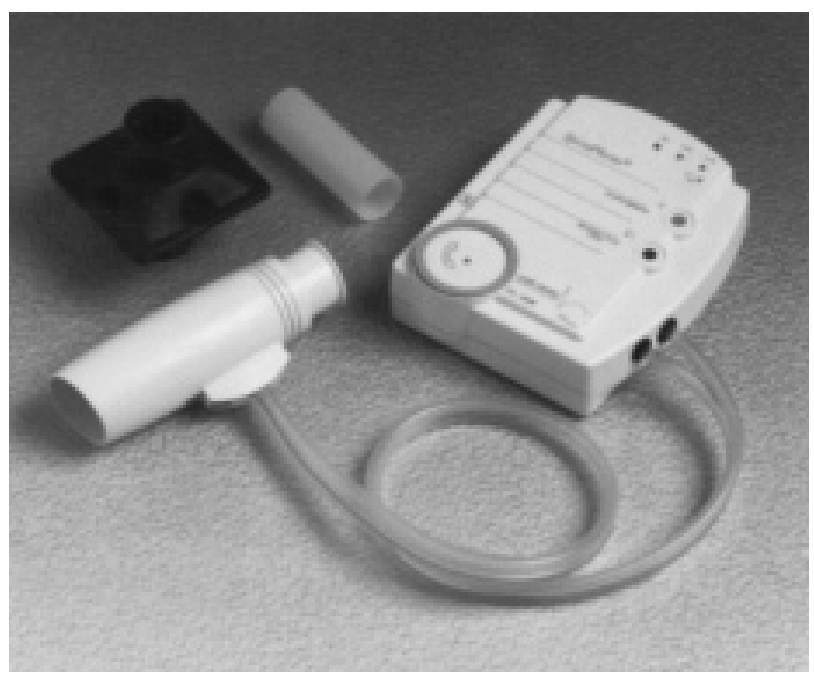

Fig. 1. - The Spirophone portable spirometer.
"Pulmonary Division, Dept of Internal Medicine, University Hospital, Basel, Switzerland. *Dept of Biomedical Engineering, Tel Aviv University, Tel Aviv, Israel.

Correspondence: C.T. Bolliger

Dept of Internal Medicine

Faculty of Medicine

University of Stellenbosch

19063 Tygerberg

7505

Republic of South Africa

Fax: 27219323105

Keywords: Asthma

flow-volume curve

home-monitoring

spirophone

telemedicine

Received: June 31998

Accepted after revision January 261999
Rishon Le Zion, Israel) with which a slow vital capacity (SVC) as well as a forced expiratory vital capacity can be recorded and telephonically transmitted to a remote receiving centre could help to resolve this problem. The aim of the present study was to compare the Spirophone to a standard laboratory spirometer (Masterlab 4.0; Jaeger AG, Würzburg, Germany) according to the American Thoracic Society (ATS) guidelines $[4,5]$. Previous studies have been able to show the reliability of the spirophone by preliminary testing [6-8].

\section{Materials and methods}

\section{Test device}

The Spirophone system records the SVC and forced vital capacity (FVC) tests. It operates with one $9 \mathrm{~V}$ battery and the data are digitized with a 12 bit analogue to digital converter with a sampling rate of $400 \mathrm{~Hz}$. The Spirophone measures flow rates using a Fleisch-type pneumotachometer, and the flow-time curve is entered into the memory. The Spirophone can then perform an integration procedure, from which the volume-time curve is obtained. It allows the transmission of data, one test at a time, through a telephone using acoustic coupling to a receiving centre. The spirometric data, transmitted to the receiving centre are displayed on a computer screen as the volume-time and the flow-volume curves from the forced expiratory manoeuvre. The following parameters are calculated from the 
curve: SVC, FVC, forced expiratory volume in one second (FEV1), FEV1/vital capacity (VC), FEV1/FVC, forced expiratory volume in three seconds (FEV3), FEV3/VC, FEV3/FVC, PEF and the maximal expiratory flow when 75,50 and $25 \%$ of the FVC remain to be expired (FEF75, FEF50, and FEF25, respectively). FEV1 and FEV3 are obtained by back extrapolation as recommended by the ATS [5]. All parameters are displayed in absolute values and in per cent of predicted normal values. The results from each patient are stored in a database program with software for data management (Card Guard Scientific Survival Ltd., Rishon Le Zion, Israel). The receiving centre requires a 486 personal computer with four megabytes of random access memory, a receiving demodulator unit, and a printer. On receiving a call from a patient, an operator at the receiving centre instructs the patient to transmit the data by placing the phone handset on to the Spirophone's speaker. The receiving unit demodulates the data, performs a body temperature and pressure saturated condition (BTPS) correction [9], and displays it on screen with the spirogram and flow-volume curve. If the exhalation is deemed acceptable according to the ATS recommendations $[4,5]$ it is stored in the database and the patient can then be instructed with respect to further exhalations or the clinical management. The program recalls previous respiratory curves from a memory and displays windows with the patient's personal data and clinical history. Comparison of pre- and postmedication spirometric data can be displayed.

\section{Patients}

Patients eligible for this study were routine patients from the authors' Division intended for the measurement of a full pulmonary function (comprising the SVC and the forced flow-volume curve with FVC, FEV1 and PEF). The device was tested on 30 patients and 15 healthy human subjects ( 21 females and 24 males, age range 24-73 yrs; mean $48.8 \pm 13.3 \mathrm{yrs}$ ) according to the ATS standards [4, 5].

\section{Trial Design}

The Spirophone was compared with a commercial standard spirometer (Masterlab 4.0). Three out of 10 available Spirophones had been selected at random. The Spirophones selected for testing were production models. The testing procedures were performed according to the ATS testing guidelines $[4,5]$. In order to achieve a balanced design, each subject performed alternating man- oeuvres between the standard spirometer and the Spirophone, performing three manoeuvres on each device, for a total of six manoeuvres. Each subject was randomly assigned to perform the first manoeuvre either on the standard spirometer or on the device being tested, allowing the learning effect to be equally distributed across both instruments. The recordings of the Spirophone were transmitted telephonically to the remote receiving centre which was in the same institution but in a different section. A trained technologist received the data, which were redisplayed instantly on a computer screen, and decided if the curves were acceptable.

\section{Statistical analysis}

All curves from both devices were assessed as to their acceptability and reproducibility according to the ATS criteria. The best value from all acceptable curves of each device was compared for SVC, FVC, FEV1 and PEF. The FEF75, FEF50, and FEF25 were compared from the best test (test with the highest sum of FVC + FEV1) of each device.

In order to test whether the measurements of the Spirophone correlated with those from the Jaeger device, the correlation coefficient ( $r$ ) between the data obtained from both devices was calculated. To further elucidate whether the measurements of both spirometers can be used interchangeably, the mean of the differences between the indices measured by both devices ( \pm limit of agreements), was calculated as described by BLAND and AltMan [10].

\section{Results}

Forty-three out of 45 curves were acceptable (two patients were not able to perform a third manoeuvre with the Spirophone because of fatigue) and the analysis was therefore performed with 43 patients. The ATS-reproducibility criteria (FEV1 and FVC of the best and second best curve of each device differing $<5 \%$ or $<200 \mathrm{~mL}$ ) were not met by four out of $28(14 \%)$ patients with the Jaeger (this criteria was met by all 15 healthy subjects) and by five out of 28 $(18 \%)$ patients as well as by five out of $15(33 \%)$ healthy subjects, with the Spirophone. As defined by the ATS, the reproducibility criteria were not used for excluding results from reports or for excluding subjects from this study [4]. The measurements of SVC, FVC, FEV1, PEF, FEF75, FEF50, and FEF25 performed with the Spirophone correlated closely with the results of the Jaeger system (all rvalues $>0.9$ ) (table 1). Figure 2 shows the correlations of

Table 1. - Correlation and limits of agreement analysis

\begin{tabular}{lcccccc}
\hline Spirometric index & Spirophone & Jaeger & Correlation coefficent & Differences* & Limits of agreement & p-value \\
\hline SVC L & $3.82(1.20)$ & $3.88(1.19)$ & 0.98 & $0.07(0.26)$ & $-0.44-0.59$ & NS \\
FVC L & $4.10(1.32)$ & $3.77(1.15)$ & 0.96 & $-0.30(0.40)$ & $-1.10-0.50$ & NS \\
FEV1 L & $3.03(1.19)$ & $2.82(1.01)$ & 0.98 & $-0.22(0.27)$ & $-0.76-0.32$ & NS \\
PEF L $\cdot \mathrm{s}^{-1}$ & $8.74(2.94)$ & $8.07(2.37)$ & 0.92 & $-0.66(1.18)$ & $-3.01-1.71$ & $\mathrm{NS}$ \\
FEF25 L·s & $6.80(3.16)$ & $5.19(2.33)$ & 0.91 & $-1.61(1.44)$ & $-4.45-1.23$ & $<0.01$ \\
FEF50 L $\cdot \mathrm{s}^{-1}$ & $3.86(2.36)$ & $2.77(1.65)$ & 0.95 & $-1.09(0.96)$ & $-3.01-0.83$ & $<0.05$ \\
FEF75 L $\cdot \mathrm{s}^{-1}$ & $1.48(1.19)$ & $0.96(0.76)$ & 0.95 & $-0.52(0.52)$ & $-1.56-0.52$ & $<0.05$ \\
\hline
\end{tabular}

Data are presented as mean (SD). *: mean Jaeger reading - mean Spirophone reading. SVC: slow vital capacity; FVC: forced vital capacity; FEV1: forced expiratory volume in one second; PEF: peak expiratory flow; FEF25, FEV50 and FEF75: forced expiratory flow at 25,50 and $75 \%$, respectively, of FVC. 
a)

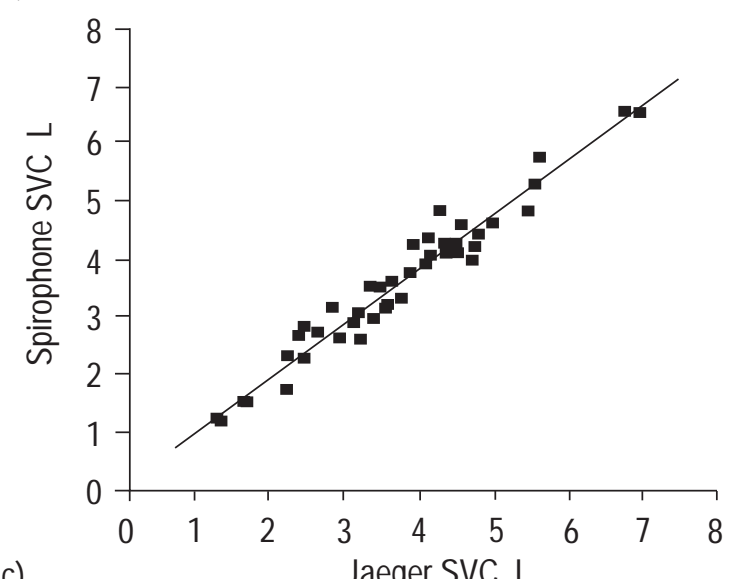

c)

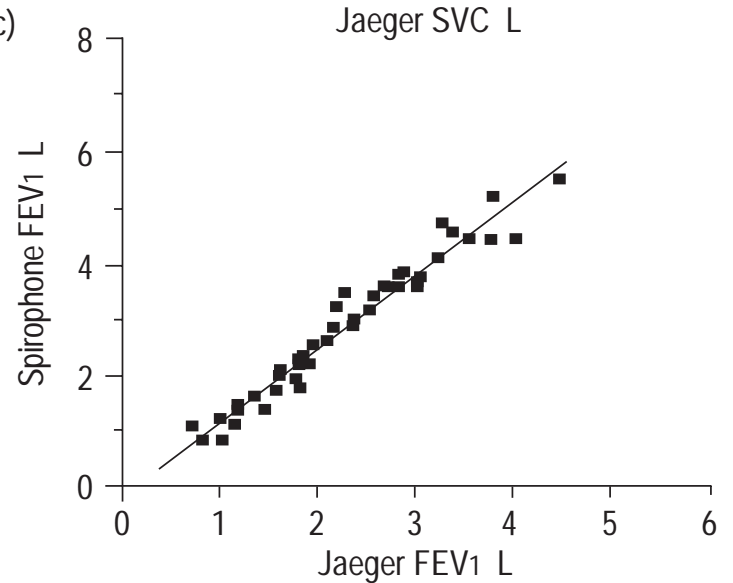

b)
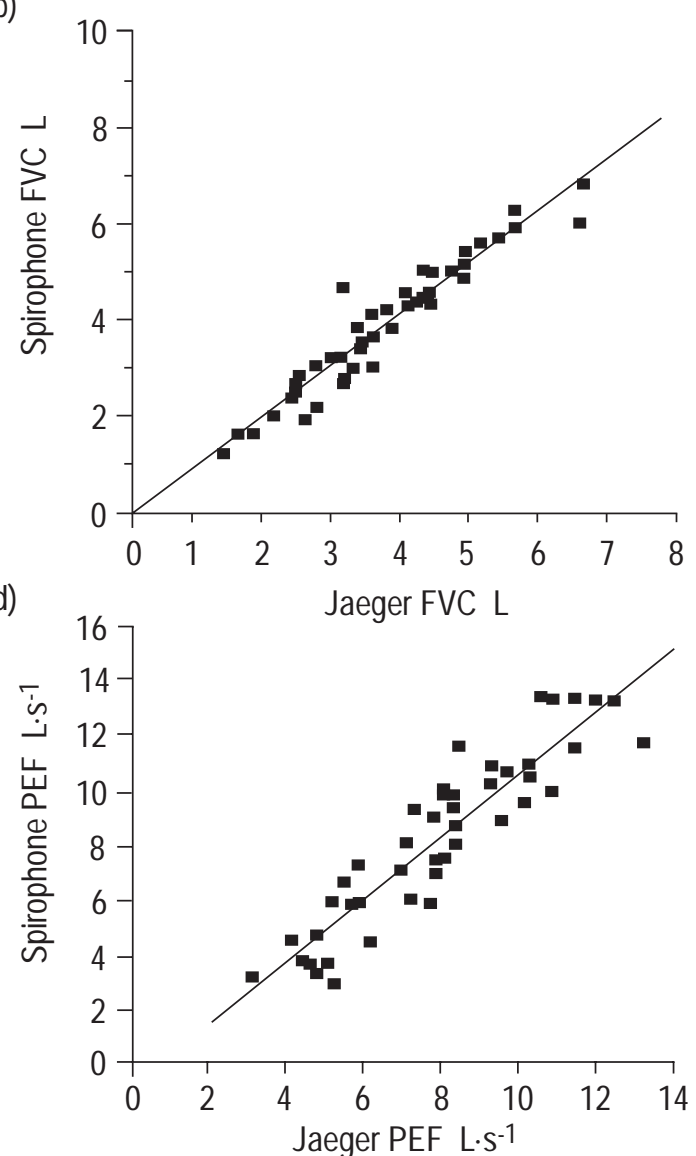

Fig. 2. - Correlation of the: a) slow vital capacity (SVC, $\mathrm{r}=0.98)$, b) forced vital capacity (FVC, $\mathrm{r}=0.96)$, c) forced expiratory volume in one second $(\mathrm{FEV} 1, \mathrm{r}=0.98)$, and $\mathrm{d}$ ) peak expiratory flow (PEF, $\mathrm{r}=0.92)$ measurements of the 43 patients using the Spirophone versus the Jaeger. Regression lines are shown.

SVC, FVC, FEV1, and PEF measured with the Spirophone versus the Jaeger for the 43 subjects who met the acceptability criteria. Figure 3 shows the plots of the differences between the readings of two spirometers against their mean for SVC, FVC, FEV1, and PEF. For SVC, FVC, FEV1, and PEF, the differences were not significant, whereas for FEF75, FEF50, and FEF25 the values obtained with the Spirophone were significantly higher than the ones from the Jaeger (table 1).

\section{Discussion}

The results show that all Spirophone measurements of FVC, SVC, FEV1, PEF, FEF75, FEF50, and FEF25 correlate closely with the results of the Jaeger system. However, FEF25, FEF50 and FEF75 were significantly higher with the Spirophone. These differences between the spirometers in flow rates and the fact that the Spirophone showed nonsignificant lower readings for SVC but higher readings for FVC are probably due to nonlinearity of the pneumotachometer. Usually the calibration procedure is performed at low flow and as a result the parameter calculated during the SVC test (low flow) is accurate. When the pneumotachometer is nonlinear it is not calibrated for high flows and the parameters calculated during the FVC test are less accurate. In order to use the Jaeger system as a standard spirometer it is necessary to eliminate any systematic bias in its calibration. This was not performed in this study. In a study by JoHns et al. [11], it was found that the Jaeger system showed a nonlinear relationship between both FEV1 and peak expiratory flow rate (PEFR) and their respective pulmonary waveform generator reference values. It was concluded that the reading on subjects must be adjusted to account for the systematic bias in their respective calibrations. This information was not available for the present study, and it was assumed that no systematic errors are present in the Jaeger system.

Because humans have their own inherent variability with repeated exhalations [12], and since the results of the FVC test show a significant reliance on patient's effort, the wider level of agreement observed with certain indices may be expected. In the limits of agreement analysis, the difference against the mean is plotted since the true value of the mean is not known. The mean of the two measurements is the best estimate available [10], and the consistent observation that the Spirophone shows higher readings for all the FVC spirometric indices may be a result of a calibration problem.

The Spirophone has previously been shown $[6,7]$ to be reliable and accurate in both the recording and transmission of forced expiratory manoeuvres from a patient's home to a remote centre for analysis and comment. Such a system being free of problems in day-to-day use under 

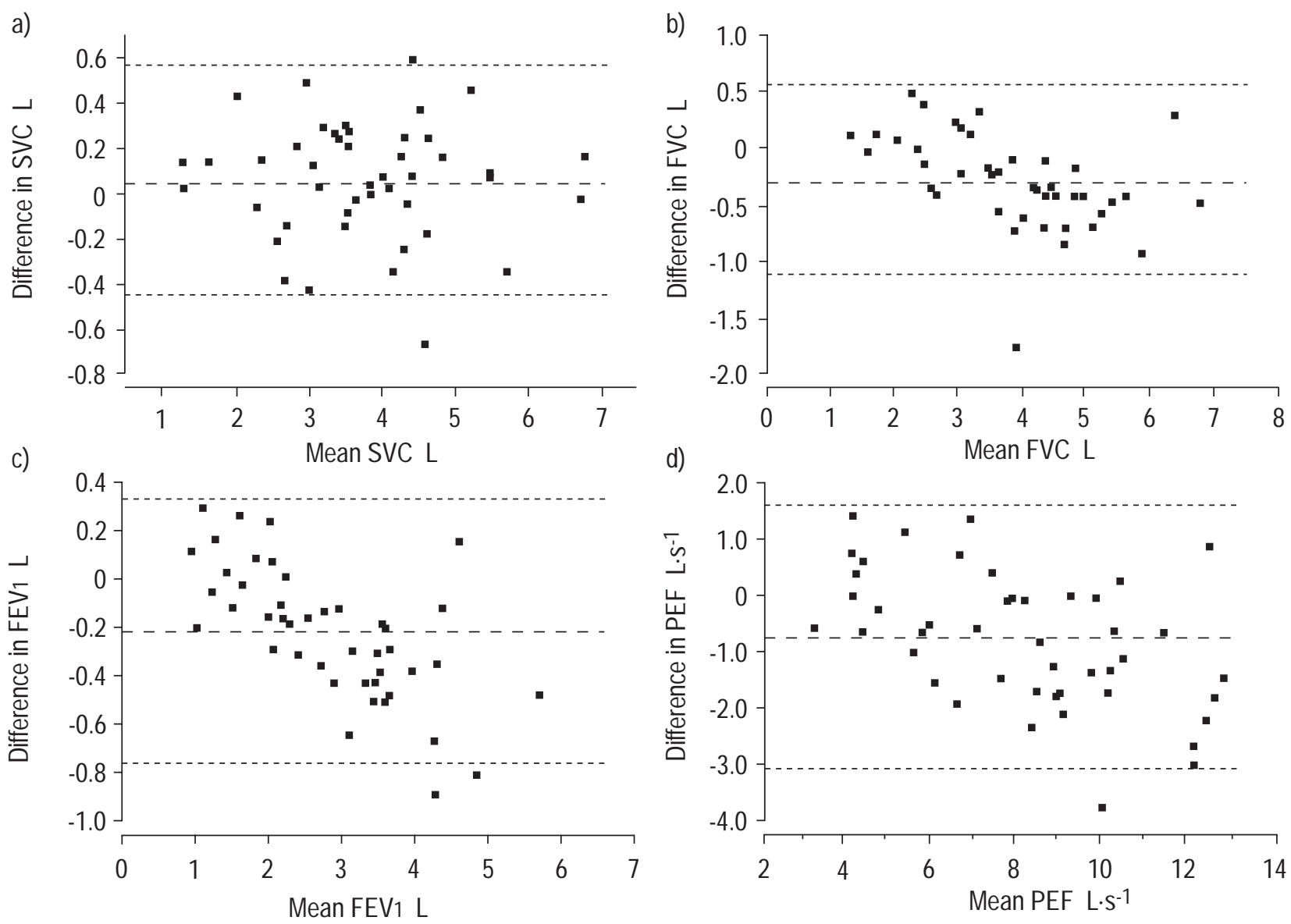

Fig. 3. - Plots of the difference between the readings of the two spirometers against their mean for: a) slow vital capacity (SVC), b) forced vital capacity $(\mathrm{FVC}), \mathrm{c})$ forced expiratory volume in one second (FEV1), and d) peak expiratory flow (PEF). The mean (-- - ) and upper and lower control limits $( \pm 2$ $\mathrm{SD} ;$ - - -) are shown.

circumstances where it cannot be specially protected and serviced by trained personnel, and including the possibility of instant expert advice, should be able to improve the current inherent problems of asthma therapy and other respiratory diseases such as cystic fibrosis, follow-up after lung transplantation and therapeutic bronchoscopy. Understanding of asthma self-management has developed greatly during the past $15 \mathrm{yrs}$, and there is a worldwide consensus that more effective methods of patient selfeducation and an objective measure of lung function at home are needed to reduce both morbidity and mortality from the disease [13-16]. Many trials have confirmed the utility of peak flow monitoring associated with an educational programme in reducing morbidity, improving lung function, and optimizing the use of medication in adult asthma patients [12, 17-22].

However, these devices are inadequate because they measure only one parameter, the PEF, which indicates airflow changes in large airways only, and they have no visual display of the spirographic curves and thus lack the ability to evaluate the patient's cooperation. The main problem stems from the fact that PEF measurements can be very unreliable [12, 23, 24]. The Spirophone monitors function of both the large and small airways. Moreover, on the basis of the shape of the transmitted flow-volume curve, the operator at the receiving centre can assess whether the forced expiratory manoeuvre was correctly performed and therefore the Spirophone, combining the advantage of home monitoring with remote quality control, can be a big help.

In young asthmatics, home monitoring of PEF twice daily correlates well with clinical indices of asthma and rescue bronchodilatator consumption in those with more severe disease, but poorly in those with mild asthma [25]. UWYYED et al. [25] concluded that better methods of obtaining objective information on the status of ambulatory patients are required, especially for the less severe asthmatics, possibly by real time monitoring of the forced expiratory flow-volume curve, symptoms and drug consumption. It has also been shown that the use of daily home spirometry when monitoring single lung recipients with emphysema as well as in patients following heart-lung transplantation offered early detection of complications such as acute lung rejection and opportunistic infections, allowing early transbronchial lung biopsy as well as assessment of their therapy [26-28]. Thus, a small portable spirometer that is easy to use such as the Spirophone, and capable of monitoring patient compliance, symptoms and both large and small airway function, may offer clear advantages. This would be especially true for patients living in remote areas or for those who have difficulty in reaching medical help due to disability or 
other reasons. The fact that the Spirophone can store and transmit only one test at a time makes it more suitable for monitoring patients with severe respiratory problems. This device would also be very useful for clinical trials and other research studies.

Although frequent use of the Spirophone is associated with higher costs (device cost and need for more personnel at the receiving centre) the authors believe that its use could save money in general patient management. In the authors' experience, the use of the Spirophone, especially in severe asthmatics, cystic fibrotics, occupational diseases and in patients after interventional bronchoscopy [29], was associated with a decrease in consultations (urgent, night, weekend and emergency-room consultations) and in laboratory pulmonary function measurements. It is still not clear if this decrease counterbalances the supplementary costs associated with a widespread use of the Spirophone.

In conclusion, these results demonstrate that the Spirophone is comparable to standard laboratory spirometry for home monitoring of forced vital capacity, slow vital capacity, forced expiratory volume in one second, and peak expiratory flow. The validity of the manoeuvre can be assessed on screen in the centre in real time and when necessary, expert advice can be transmitted.

Acknowledgements. The authors would like to thank G. Herkstroeter, M. Leo, G. Luedin, and E. Sohm of the lung function laboratory for their cooperation.

\section{References}

1. Cote J, Cartier A, Robichaud P, et al. Influence on asthma morbidity of asthma education programs based on selfmanagement plans following treatment optimization. $\mathrm{Am}$ J Respir Crit Care Med 1997; 155: 1509-1514.

2. van-Schayck CP, Dompeling E, Putters R, Molema J, van-Weel C. Asthma and chronic bronchitis. Can family physicians predict rates of progression? Can Fam Physician 1995; 41: 1868-1876.

3. Lurie A, Vlastos FD, Dusser DJ, Strauch G, Marsac J. Long-term management of reversible obstructive airways disease in adults. Lung 1990; 168: Suppl. 154-167.

4. American Thoracic Society. Standardization of spirometry, 1994 update. Am J Respir Crit Care Med 1995; 152: $1107-1136$.

5. American Thoracic Society. Standardization of Spirometry, 1987 Update. Am RevRespir Dis 1987; 136: 1285-1298.

6. Abboud S, Bruderman I. Assessment of a new transtelephonic portable spirometer. Thorax 1996; 51: 407-410.

7. Bruderman I, Abboud S. Telespirometry: a novel system for home monitoring of asthmatic patients. Telemed $J$ 1997; 3: 127-133.

8. Bolliger CT, Gonon M, Abboud S, Bruderman I, Perruchoud AP. The accuracy of the spirophone, a novel transtelephonic portable spirometer. Eur Respir $J$ 1996; 9: Suppl. 23, 469S.

9. Turney SZ, Blumenfeld W. Heated Fleisch pneumotachometer: a calibration procedure. J Appl Physiol 1973; 34: $117-121$.

10. Bland JM, Altman DG. Statistical methods for assessing agreement between two methods of clinical measurement. Lancet 1986; 8: 307-310.

11. Johns DP, Abramson M, Bowes G. Evaluation of a new ambulatory spirometer for measuring forced expiratory volume in one second and peak expiratory flow rate. $\mathrm{Am}$ Rev Respir Dis 1993; 147: 1245-1250.

12. Miller MR, Dickinson SA, Hitchings DJ. The accuracy of portable peak flow meters. Thorax 1992; 47: 904-909.

13. O'Bey KA, Jim LK, Gee JP, Cowen ME, Quigley AE. An education program that improves the psychomotor skills needed for metaproterenol inhaler use. Drug Intell Clin Pharm 1982; 16: 945-948.

14. Heringa P, Lawson L, Reda D. The effect of a structured education program on knowledge and psychomotor skills of patients using beclomethasone dipropionate aerosol for steroid dependent asthma. Health Educ Q 1987; 14: 309317.

15. Clark NM. Asthma self-management education. Research and implications for clinical practice. Chest 1989; 95: 1110-1113.

16. Goldstein RA, Geen LW, Parker SR. Self-management of childhood asthma. J Allergy Clin Immunol 1983; 75: 522 525 .

17. Ignacio-Garcia JM, Gonzalez-Santos P. Asthma selfmanagement education program by home monitoring of peak expiratory flow. Am J Respir Crit Care Med 1995; 151: 353-359.

18. Harm DL, Kotses H, Crer TL. Improving the ability of peak expiratory flow rates to predict asthma. $J$ Allergy Clin Immunol 1985; 76: 688-694.

19. Janson-Bjeklie S, Shnell S. Effect of peak flow information on patterns of self-care in adults. Heart Lung 1988; 17: 543-549.

20. Charlton I, Charlton G, Broomfield J, Mullee MA. Evaluation of peak-flow and symptoms only self-management plans for control of asthma in general practice. BMJ 1990; 301: 1355-1359.

21. Beasley R, Cushley M, Holgate ST. A self management plan in the treatment of adult asthma. Thorax 1989; 44: 200-204.

22. Fishwick D, Beasley R. Use of peak flow-based selfmanagement plans by adult asthmatic patients. Eur Respir $J$ 1996; 9: 861-865.

23. Quirce S, Contreras G, Dybuncio A, Chan-Yeung M. Peak expiratory flow monitoring is not a reliable method for establishing the diagnosis of occupational asthma. Am J Respir Crit Care Med 1995; 152: 1100-1102.

24. Verschelden P, Cartier A, L'Archeveque J, Trudeau C, Malo J-L. Compliance with and accuracy of daily selfassessment of peak expiratory flows (PEF) in asthmatic subjects over a three month period. Eur Respir J 1996; 9: $880-885$.

25. Uwyyed K, Springer C, Avital A, Bar-Yishay E, Godfrey S. Home recording of PEF in young asthmatics: does it contribute to management? Eur Respir J 1996; 9: 872-879.

26. Bjortuft O, Johansen B, Boe J, Foerster A, Holter E, Geiran O. Daily home spirometry facilitates early detection of rejection in single lung transplant recipients with emphysema. Eur Respir J 1993; 6: 705-708.

27. Otulana BA, Higenbottam T, Ferrari L, Scott J, Igboaka G, Wallwork J. The use of home spirometry in detecting acute lung rejection and infection following heart-lung transplantation. Chest 1990; 97: 353-357.

28. Finkenlstein SM, Lindgren B, Prasad B, et al. Reliability and validity of spirometry measurements in a paperless home monitoring diary program for lung transplantation. Heart Lung 1993; 22: 523-533.

29. Bolliger CT, Wyser C, Perruchoud AP. Telemedicine in the postinterventional surveillance of patients with central airway obstruction. Eur Respir J 1998; 12: Suppl. 28, 266S. 